\title{
Quality of Life Is Correlated to Anemia in Children and Adolescent Undergoing Hemodialysis
}

\author{
Raghad Hussein Abdelkader ${ }^{1,2}$ \\ ${ }^{1}$ College of Nursing Applied Science Private University, Amman, Jordan \\ Correspondence: Raghad Hussein Abdelkader, Assistant Professor, Amman, 11934, Jordan. Tel: \\ 962-777-338-509; Fax: 96-265-232-899. E-mail: r.abdelkader96@yahoo.com; r_abdelkader@asu.edu.jo
}

Received: July 19, 2018 Accepted: September 3, 2018 Online Published: September 11, 2018

doi:10.5539/gjhs.v10n10p103 URL: https://doi.org/10.5539/gjhs.v10n10p103

\begin{abstract}
Introduction: Anemia is a common symptom of end stage renal disease in children and adolescents. Anemia is one factor for patients with end stage renal disease that have an effect on quality of life. Therefore, the purpose of this study was to examine the correlation between the hemoglobin level and quality of life and fatigue level for children and adolescent in Jordan.

Materials and Methods: A cross-sectional correlational design was used. A total of 121 children and adolescences were recruited from hemodialysis units at seven hospitals of three cities in Jordan. Data collected through the 34-item Pediatric Quality of Life Inventory 3.0 End-Stage Renal Disease (PedsQL 3.0 ESRD questionnaire.

Results: The results of this study demonstrated that $38(31.4 \%)$ school-age children their age ranged from 6 to 12 years old, while adolescents (13-20) years old 83 (68.6\%), and 67 (55.4) of them were female. Children and adolescents with ESRD reported low mean hemoglobin level over 7 months below 11.1g/dlSD (1.9). A significantly negative correlation between the PedsQL total scores with mean hemoglobin levels $\mathrm{p}<0.05$ was reported, and positive correlation with fatigue sub-score $\mathrm{p}<0.05$.
\end{abstract}

Conclusions: It is essential for nurses and patients to recognize the relationship between anemia and low quality of life and high fatigue level for end stage renal disease children and adolescent patients. Finding of current study are facilitating to design especial program for improve the nutritional and health status for those ESRD patients.

Keywords: anemia, children and adolescents, ESRD, fatigue, Jordan, quality of life

\section{Introduction}

There is a percent of the population of the United Kingdom and many American state have end stage renal disease (National Institute for Health and Care Excellence (NICE), 2015). Padhi, (2015) reported that based on world health organization criteria around fifteen percent of these adult patients are having decrease in their hemoglobin level below normal level to age. Kidney Disease Initiative Quality Outcomes KDIGO, (2012) found in its survey that there were more than 100.000 people in the UK have low hemoglobin level who complaining of chronic kidney disease. Low hemoglobin below normal level to age is considered anemia (Hockenberry, Rodgers, \& Wilson, 2017). This could be happen related to many factors as renal disease that leads to erythropoietin deficiency; other causative factors include blood loss, infection or inflammation, or nutritional deficiency such as some mineral that contribute production of hemoglobin as iron, folate, or/and vitamin B12 (Koshy \& Geary, 2006; Kliger et al., 2013).

In Jordan the country of Eastern Mediterranean region, is considered one of the countries that have moderate significance anemia prevalence (20-39.9\% of public health problem)/ hemoglobin level less than $12 \mathrm{~g} / \mathrm{dl}$ (Benoist, McLean, Egli, \& Cogswell, 2008). But there was no specific statistical number found related to low hemoglobin level for children and adolescents with end stage renal disease ESRD.

Severe anemia -in school-age children and adolescents - could be influence many aspects of quality of Life such as physical, cognitive, spiritual and psychosocial (Bunn, 2011). Anemic in children and adolescents may release a shortened attention span and decreased awareness (Geer et al., 2017). Likewise, anemia is a major end result ESRD in school-age children and adolescents; It is linked with cardiovascular dysfunction, cardiomyopathy and left ventricle mass, and consequently to death (Bunn, 2011; Janus \& Moerschel, 2010; KDOQI, 2012). 
The national of kidney foundation on (NKF, 2006) considered a hemoglobin level less than $12.1 \mathrm{~g} / \mathrm{dL}$ for females and $13.8 \mathrm{~g} / \mathrm{dL}$ for males is anemic (NKF KDOQI, 2006). Another foundation for ESRD on (2007) recommended hemoglobin level regardless the gender to be 11.0-12.0 g/dL (NKF KDOQI). This is lower than the known level for healthy females which is 12.1-15.1 g/dL, and males 13.8-17.2 g/dL (WHO, 2008). NKF KDOQI recommended this related to the sequelae effect of high hemoglobin level on cardiac procedures notice in adults. NKF KDOQI recognizes death in some cases related to complication as coronary artery calcification in children.

Hemodialysis is a procedure used to replace the kidney function to maintain health status by many children and adolescent with ESRD; (Nesrallah et al., 2014). End stage renal disease and its treatment of hemodialysis bargain to and increase risk of a low hemoglobin (Ellis et al., 2010, Locatelli et al., 2013). Low hemoglobin or anemia is interrelated to an increase in fatigue and which later will shape the quality of life (Ingulli \& Mak, 2014; Kogon et al., 2016).

There are assumptions related to low hemoglobin level for ESRD school-age children and adolescents. One is related to nutritional mineral (iron) intake deficiency and other due to chronic blood loss, Koshy and Geary (2006) \& Kliger et al., (2013). Koshy \& Geary (2006) stated in their study that hemodialysis patients are at risk for iron deficiency anemia due to decrease intake of iron. Kliger et al., (2013) reflected this low hemoglobin level due to blood loss from repeated blood sampling and through the hemodialysis process in the dialyzers and tubing that lead to the shortened life span of the red blood cell. Other factor is due to renal disease that leads to erythropoietin deficiency which is created in the kidneys and responsible for stimulating hemoglobin production (Clarkson \& Robinson, 2010; Bunn, 2011; Glader, 2007; Wang, 2016). Other causes: vitamin deficiency, inflammation, medications, ineffective dialysis, and other chronic disease (Warady, Neu, \& Schaefer., 2014).

Fatigue is the major widespread symptom of anemia (Chao, 2016). Jhamb et al., (2009) conducted a study on patients with ESRD undergoing long term hemodialysis therapy. Their result reviled that $60-97 \%$ of patients have high level of fatigue (Jhamb et al., 2009). Jhamb et al., (2009) stated that fatigue in hemodialysis adult may be had many factors. Most important factor is anemia other are, such as, uremia, hyperparathyroidism, dialysis inadequacy co-morbidity, depression, sleep disorders, side effects of medication some of the factors contributing to fatigue can be "anemia, malnutrition, uremia, physical inactivity (Jhamb et al., 2009). Fatigues influence with the daily activity of dialysis patients (Bossola, Vulpio, \& Tazza, 2011). Bossola, et al (2011) found fatigue to be is one of four warning sign which can decline the quality of life for ESRD patients, the others being depressed, pain, and lack of well-being. Social and psychological well-being; the other aspects of quality of life also; have a significant impact that could be effect of ESRD patients' lives (Abdelkader, Khalil, MaSa'ada, Alklube, \& Alrimawi, 2016). Although there are many contributing factors, this study examined the relationship between anemia as evidenced by hemoglobin levels and stated fatigue scores and quality of life in school-age children and adolescents.

Most research has focused on quality of life for adults. There is insufficient in the literature related to the school-age children and adolescent population of hemodialysis particularly developing countries such as Jordan (Abdelkader et al., 2016). By succeeding school-age children and adolescents with ESRD living undergoing hemodialysis treatment; research needs to be expanded to include this population. This study looks forward to act upon this gap by focusing on school-age children and adolescents. So the purpose of this study was to examine the relationship between hemoglobin levels and quality of life as a whole; then the relationship with general fatigue as one aspect of quality of life of school-age children and adolescents under hemodialysis treatment of ESRD. (For the purpose of this study author defined school age children as 6-12 years old and adolescent $13-20$ years old).

\section{Methods}

\subsection{Design and Setting}

The current study employed a descriptive cross-sectional retrospective correlational design. Seven huge pediatric hospitals were selected to recruit a convenience sample (two private, one military, two teaching and two public hospitals). The Jordanian cities are (Amman, Irbid, and Zarqa cities). These cities provide haemodialysis services for children and adolescent patients with ESRD. These cities are including due to the highest percent of total population in Jordan that ensure the diverse demographic characteristic population.

\subsection{Sampling}

The sample size calculated by using G-power program with $\alpha$ probability of $(5 \%)$ and power of $(80 \%)$, with medium effect size of (0.15), $t$-test, ANOVA and a carrolation statistical test used, so the calculating program indicated the minimum number of sample is (103), and to minimize the effect of errors, in ordere to this study should involved at least (110) children and adolescents (Polit \& Bick, 2016). All haemodialysis children and adolescents who came to their arrangements on the scheduled time at known hemodialysis units met the inclusion 
criteria were 185 . They were encouraged for participation. The convenient sample consisted of 121 participant with response rate of $65.5 \%$.The inclusion criteria for school age children and adolescent who have confirmed diagnosed with end stag renal disease on hemodialysis for at least five months. They have registration to one of the seven hospitals included in the study. Children and adolescent with age 20 years or younger, able to verbally communicate and interview with researchers and willing to participate in the study. Excluded from the sample any child or adolescent who have coexisting terminal illness, or who has reduce the session time less than 10 minutes or omitted the hemodialysis sessions in the previous two weeks without medical-related reasons.

\subsection{Data Collection Procedure}

The best time was chosen to apply the questionnaires at the beginning of the dialysis session. The principle investigator explained the aim of the study and the process of filling self-reporting questionnaire to the adolescent $12-20$ years, or parents of the children less than 12 years. Participants were assured that they could withdraw at any time and their decision regarding taking part in this study would not affect their child's care. Parents/adolescents were invited to sign a consent form and to complete two sets of questionnaire a socio-demographic form and The Pediatrics Quality of Life PedsQL 3.0 ESRD after they agreed to participate in the study. Then patients' medical records reviewed for hemoglobin levels which have been collected in retrospective manner over previous 7months from first May, till November, 2017. There were four points of hemoglobin levels collection: on May, July, August, and November of 2017.

\subsection{Ethical Consideration}

Firstly, ethical approval from the Research Ethics committee of the Faculty of Nursing at the Applied Science Private University has beesn obtained. Another ethical approval from the Institutional Review Board (IRB) was obtained from each hospital setting as well as. The completed questionnaire were coded for analysis and kept in a double locked office.

\subsection{Measures}

A self-report questionnaire was used consist of two parts. The first part included socio-demographic information regarding, gender, frequency of dialysis/week, educational level, age, age at onset ,date on the current, and perception of health status of the patient including medical information about diagnosis (ESRD), duration of illness, type of treatment, , family history, complications or other diseases, lab result such as hemoglobin level and prescribed medication. The second part is Arabic version of Pediatrics Quality of Life PedsQL 3.0 ESRD Module form which get translation and back translation with Cronbach's Alpha .82 (Abdelkader,et al 2016). PedsQL 3.0 ESRD Module cover seven scales,: a- General Fatigue (4) items), b- Treatment Problems (4 items), c- Family and Peer Interaction (3 items), d- About My Kidney Disease (5 items) e- Communication (5 items), f- Perceived Physical Appearance ( 3 items), and g- Worry (10 items). All of them are 34 items and uses a 5 point Likert scales. Total Score: Sum of all the items over the number of items answered on all the scales, with zero being the best quality of life rating. Reliability of the PedsQL ${ }^{\mathrm{TM}}$, as reported by Goldstein, et al , 2008, Goldstein, et al, 2009) "exceeded the minimum reliability standard of 0.70 ".

\subsection{Analysis Plans}

The Statistical Package for Social Sciences version 22.0 (SPSS, Inc., Chicago, IL, USA) were used to analyzed Data. Data were organize and summarize by used a descriptive statistics including mean scores and standard deviation (SD). To determine the relations between hemoglobin level, and several demographic variables: age, gender, level of education, and QoL; Inferential statistics such as, analysis of variance (ANOVA), and independent $t$-tests to compute differences between the variables was used as well as Pearson correlations. A significant $P$-value considered being 0.05 or less (Polit \& Beck, 20116).

\section{Results}

The purpose of this study was to examine the relationship between hemoglobin levels and quality of life scores of school-age children and adolescents on hemodialysis for treatment of end stage renal disease. A descriptive cross sectional correlational study of 121 convenience Jordanian school-age children and adolescents on hemodialysis was shared in this study from 7 major pediatric hospitals of three cities in Jordan. Of the 121 patients, there were 54 (44.6\%) males and 67 (55.4\%) females (Table 1). School-age children ranged from 8 to 12 years old 38 (31.4\%) and adolescents $13-20$ years old 83 (68.6\%). In the present study, the mean duration of dialysis is 42.18 month $\mathrm{SD}=$ 30.57. The frequency of dialysis ranged between children and adolescent from 1 time to 7 times per week, with a mean of 3.29. The sample varied in the level of education (Table 1). 
Table 1. Frequency of participants according to sociodemographic factors

\begin{tabular}{ll}
\hline Participants demographics & $\mathbf{f} \%$ \\
\hline Educational level: & $35(28.9 \%)$ \\
Early elementary school (1 -6) grade & $51(42.1 \%)$ \\
Late elementary school (7-10) grade & $35(28.9 \%)$ \\
Secondary school (1-2) grade & $2(1.7 \%)$ \\
\hline Smoking: & $119(98.3 \%)$ \\
Yes & \\
No & $54(44.6 \%)$ \\
\hline Gender: & $67(55.4 \%)$ \\
Male & \\
Female & $38(31.4 \%)$ \\
\hline Age: years & $83(68.6 \%)$ \\
Children: $8-12$ & \\
Adolescent: $13-20$ & $54(44.6 \%)$ \\
\hline Vascular access & $67(55.4 \%)$ \\
Central line &
\end{tabular}

A total of 150 questionnaires were distributed; 29 of them have missed a lot of the data that could not be included in the analyses. A 2-tailed Pearson's correlation was ran on the 121 completed questionnaires to examine the relationship between the PedsQLTM quality of life total score and the hemoglobin level from the consequent time frame (Table 2). A negative Pearson's $r$ significance correlation at $\mathrm{p}<0.05$. The total score was calculated by sum of all the items over the number of items answered on all the scales. The total possible score on the PedsQLTM ranged from $0-136$, with zero being the best quality of life rating. The scores ranged from 22-97. The mean quality of life scores 37.1with SD (15.8). The mean hemoglobin level ranged from 10.2, SD (1.8) to 11.1, SD (1.9). A negative correlation was noted between the PedsQL total scores and the mean hemoglobin levels $\mathrm{p}<0.05$.

Table 2. The Correlation between PedsQL ${ }^{\mathrm{TM}}$ total score and Hemoglobin levels (Pearson $r$ correlation)

\begin{tabular}{llllll}
\hline Time month/2017 & Participants & Hemoglobin level, SD & QoL, SD & $r$ & $P$ value \\
\hline May & 121 & $10.5(2.1)$ & $37.1 .(15.8)$ & $-.397^{* *}$ & .000 \\
July & 119 & $10.4(2.1)$ & $37.1 .(15.8)$ & $-.390^{* *}$ & .000 \\
August & 106 & $10.2(1.8)$ & $37.1 .(15.8)$ & $-.301^{* *}$ & .002 \\
November & 67 & $11.1(1.9)$ & $37.1 .(15.8)$ & -.193 & .117 \\
\hline
\end{tabular}

*. Correlation is significant at the 0.05 level (2-tailed).

**. Correlation is significant at the 0.01 level (2-tailed).

QoL: quality of life, SD: standard deviation.

A total of 121 questionnaires included in a 2-tailed Pearson's correlation for examining the relationship between the General Fatigue sub-score and the hemoglobin level over four months (Table 3). The total possible score on the General Fatigue sub score ranged from 0-16, with zero representing fatigue "never" being a problem and 16 representing fatigue as "almost always" being a problem. The scores ranged from $0-13$. The mean of the general fatigue sub scores $8.57 \mathrm{SD}$ (3.5). The mean hemoglobin level ranged from 10.2SD (1.8) to 11.1SD (1.9) with a Pearson's $r$ significance of $\mathrm{p}<0.05$, a positive significance correlation was found. 
Table 3. The Correlation between the Hemoglobin levels and General Fatigue. (Pearson $r$ correlation)

\begin{tabular}{llllll}
\hline Time month $/ 2017$ & Participants / N & Hemoglobin level, SD & Fatigue score, mean/SD & $r$ & $P$ value \\
\hline May & 121 & $10.5(2.1)$ & $8.57(3.5)$ & $.276^{* *}$ & .002 \\
July & 119 & $10.4(2.1)$ & $8.57(3.5)$ & $.251^{* *}$ & .006 \\
August & 106 & $10.2(1.8)$ & $8.57(3.5)$ & $.210^{*}$ & .031 \\
November & 67 & $11.1(1.9)$ & $8.57(3.5)$ & .083 & .506 \\
\hline
\end{tabular}

*. Considered signification level at 0.05 (2-tailed).

**. Considered signification level at 0.001 (2-tailed).

Another type of correlation for nonparametric variable (categorical) applied was Spearman rho correlation for examining the relationship between the hemoglobin level over four different points of time and Sociodemographic characteristic such as educational level, vascular access and children and adolescents age. The result revealed: there are a significant positive correlation between low hemoglobin level (anemia) and educational level at three points of time for example at August when mean hemoglobin level 10.2 SD=1.8. Sperman rho correlation significant at $\mathrm{P}<.001$. While there was no significant correlation between low hemoglobin level with vascular access except at May month when mean hemoglobin was $10.5 \mathrm{SD}=(2.1)$ it was significant at $\mathrm{P}<.005$. In addition to children and adolescent age there were fluctuation over the time between the correlation between low hemoglobin level and patients age as seen in Table 4.

Table 4. The Correlation between Hemoglobin level and Sociodemographic characteristics (Spearman's rho Correlation)

\begin{tabular}{|c|c|c|c|c|c|c|c|c|}
\hline \multirow{2}{*}{$\begin{array}{l}\text { Hemoglobin level/ } \\
\text { month/ } 2017\end{array}$} & \multirow{2}{*}{$\begin{array}{l}\text { Total } \\
\mathrm{N} \\
121\end{array}$} & \multirow{2}{*}{$\begin{array}{l}\text { Hemoglobin } \\
\text { mean }(\mathrm{SD})\end{array}$} & \multicolumn{2}{|c|}{$\begin{array}{l}\text { Educational level } \\
\text { rho/P value }\end{array}$} & \multicolumn{2}{|c|}{$\begin{array}{l}\text { Vascular Access } \\
\text { rho/ P value }\end{array}$} & \multicolumn{2}{|c|}{$\begin{array}{l}\text { Age } \\
\text { rho/ P value }\end{array}$} \\
\hline & & & $.381 * *$ & .000 & $.280 * *$ & .002 & $.628 * *$ & .000 \\
\hline Hb (July) & 119 & $10.4(2.1$ & $.372 * *$ & .000 & .128 & .167 & $.181 *$ & .048 \\
\hline $\mathrm{Hb}$ (August) & 106 & $10.2(1.8)$ & $.323 * *$ & .001 & .084 & .391 & .154 & .114 \\
\hline $\mathrm{Hb}$ (November & 67 & $11.1(1.9)$ & .215 & .080 & -.057 & .645 & -.034 & .785 \\
\hline
\end{tabular}

*. Considered signification level at 0.05 (2-tailed).

**. Considered signification level at 0.001 (2-tailed).

SD: standard deviation

Other inferential statistical tests applied for differentiate the differences of low mean of hemoglobin level on some of sociodemographic characteristic.

Bivariate compare mean test a one-way ANOVA was used to test for hemoglobin level among the three educational schools grades. Hemoglobin level differed significantly across them at three points in the study especially when the hemoglobin level is low. Such as when collect on July $F(2,70.928=9.847, p=.000)$. Tukey's post hoc comparisons of the three groups indicate that the hemoglobin at the secondary school grade (mean $=11.52$, $\mathrm{SD}=1.57)$ and the late elementary grade (mean $=10.4, \mathrm{SD}=2.1)$ reported significantly higher hemoglobin levels than it in the early elementary school grade (mean $=9.5, \mathrm{SD}=1.9), p=.000$ ). 
Table 4. Mean scores of hemoglobin level according to educational level. (Including f-test test)

\begin{tabular}{|c|c|c|c|c|c|c|c|}
\hline \multirow{2}{*}{$\begin{array}{l}\text { Hemoglobin } \\
\text { level/month/2017 } \\
\text { Hb (May) }\end{array}$} & \multirow{2}{*}{$\begin{array}{l}\text { Hemoglobin } \\
\text { mean (SD) } \\
10.5(2.1)\end{array}$} & \multicolumn{2}{|c|}{$\begin{array}{l}\text { Educational } \\
\text { level } \\
F / P \text { value }\end{array}$} & \multirow{2}{*}{$\begin{array}{l}\text { Early elementary } \\
\text { school } \quad\left(\begin{array}{ll}1 & -6\end{array}\right) \\
\text { grade } \\
\text { (n)/m, SD } \\
(35)\end{array}$} & \multirow{2}{*}{$\begin{array}{l}\text { Late elementary } \\
\text { school } \quad(7-10) \\
\text { grade } \\
(\mathrm{n}) / \mathrm{m}, \mathrm{SD} \\
(51)\end{array}$} & \multirow{2}{*}{$\begin{array}{l}\text { Secondary } \\
\text { school (1-2) } \\
\text { grade } \\
(\mathrm{n}) / \mathrm{m}, \mathrm{SD} \\
(35)\end{array}$} & \multirow{2}{*}{$\begin{array}{l}\text { Total } \\
\mathrm{N} \\
121 \\
\end{array}$} \\
\hline & & 10.842 & $.000 * *$ & & & & \\
\hline & & & & $9.59,1.90$ & $10.26,2.19$ & $11.75,1.77$ & \\
\hline \multirow[t]{2}{*}{$\mathrm{Hb}$ (July) } & $10.4(2.1$ & 9.842 & $.000 * *$ & (35) & (50) & (34) & 119 \\
\hline & & & & $9.49,1.90$ & $10.37,1.57$ & $11.52,1.57$ & \\
\hline \multirow[t]{2}{*}{$\mathrm{Hb}$ (August) } & $10.2(1.8)$ & 7.012 & $.001 * *$ & (32) & (42) & (32) & 106 \\
\hline & & & & $9.52,1.85$ & $9.88,2.15$ & $11.15,1.33$ & \\
\hline \multirow[t]{2}{*}{$\mathrm{Hb}$ (November } & $11.1(1.9)$ & .493 & .082 & (22) & (26) & (19) & 67 \\
\hline & & & & $9.57,2.22$ & $12.70,17.51$ & $10.74,1.21$ & \\
\hline
\end{tabular}

Note: ${ }^{*} p<_{-} .001 ; * * p<_{-} .05$.

As estimated, findings from the independent $t$-test exposed a significant difference in mean hemoglobin level for children less than 12 years (mean $=10.1, \mathrm{SD}=1.8$ ) is lower than adolescents hemoglobin (mean 10.7, $\mathrm{SD}=2.2 ; \mathrm{t}$ (119) $6.592, p=.011$ ). Another independent $t$-test was used to test the comparison mean of hemoglobin level in children using different vascular access for hemodialysis. Findings revealed a significant difference in mean hemoglobin level for children with hemodialysis vascular access through fistula and/or shunt (mean $=10.34, \mathrm{SD}=$ 2.2) higher than children with hemodialysis through central line (mean 9.93, $\mathrm{SD}=1.6 ; t(119) 10.831, p=.001$ ).

\section{Discussion}

Anemia is a general complication in children with ESRD causing many unfavorable clinical consequences, including poor quality of life, fatigue, depression, and cognitive impairment (KDIGO, 2012; Abdelkader et al., 2016).

The results of current study explain, and descibe relatively, the relationship between anemia and quality of life as a whole then general fatigue of school-age children and adolescents undergoing hemodialysis for treatment of the end stage renal disease in Jordan. Previous studies have not given the impression of being address at the special effects of different demographic variables nor have they deal with effects of demographics on levels of hemoglobin in Jordan such as (Abdelkader et al., 2016).

Finding in current study has adolescents female with ESRD undergoing hemodialysis more than male and this result is contradict with Seppi et al (2016) who found that adult female have higher resistance to renal damage related to female hormones. Children and adolescents female in current study most of them have physical growth and developmental delay. Adolescents female did not developed secondary sex characteristic such as menstrual cycle, ovulation and sex female hormone well. While Kepka et al (2008) mentioned that no differences in gender connected to causes of idiopathic nephritic syndrome in children. Whereas, Seliger, Davis, and Stehman (2001) stated in their study that many men have a more rapid progression of renal insufficiency. The following mechanisms for this gender discrepancy are potentially related to differences between the gender in glomerular structure, glomerular hemodynamic, deviations in the creation and activity of local interleukins and hormones, and/or the direct effect of female sex hormones on normal renal tissue might protect against damage (Silbiger \& Neugarten, 2003; Seppi et al., 2016). However, other studies have found no differences between the gender, and the true effect of gender on chronic renal disease remains a topic of controversy (Silbiger \& Neugarten, 2003). The differences between the genders in renal disease progression cannot be fully explained by differences in blood pressure or serum cholesterol levels (Silbiger \& Neugarten, 2003).

All school-age children and adolescent in the current study were anemic patients (over 7 months: period of the study) based on the new NKF-KDOQI clinical practice guidelines 2012 (their hemoglobin level less than 12g/dl). Finding in the current study is congruent with Gerson et al (2004) who investigated anemia and quality of life for 105 adolescents with stages 1 to 5 chronic kidney disease. Their result was anemia associated with lower quality of life in adolescents.

The current study revealed that there is a negative correlation between total scores of quality of life and the mean of 
hemoglobin levels to school-age children and adolescents. This finding is congruent with Park, et al 2012, Ingulli \& Mak., 2014; Gat-Yablonski \& Phillip, 2015). Gat-Yablonski \& Phillip 2015 mentioned in their study that anemia is one of the possibility factor that contribute to delayed growth in children and adolescent with ESRD in addition to undernourishment, metabolic acidosis, mineral and bone disorders, , and fluid and electrolyte abnormalities). Physical growth and developmental delay consequential short stature is a significant issue for quality of life in many children and adolescents with ESRD (Ingulli \& Mak., 2014; Al-Uzri et al., 2013). Ingulli \& Mak., (2014) encouraged in their study to increase nutritional need from iron and mineral metabolism, correcting anemia, to improve quality of life.

The current study revealed there is a relationship between hemoglobin level and fatigue among school-age children and adolescents with ESRD at the hemodialysis units at Jordanian hospitals. Fatigue and low quality of life is related to low hemoglobin or anemia (Ameringer, Elswick \& Smith, 2013). Ameringer, Elswick, Smith (2013) they conclude in their study that fatigue was correlated with hemoglobin level in sickled cell adolescent and young adult patients and has significant issue to low quality of life . As recorded in previous studies (Jhamb et. al., 2009), who reported that most the time children in their study were complaining of fatigue. Evidence shows that, both in different age groups adult and children, hemoglobin levels more than $13 \mathrm{~g} / \mathrm{dL}$ are associated with enhanced patient outcomes including lower mortality, less frequent hospitalization, and improve quality of life (KDOQI, 2012).

The current finding revealed there are significant differences in mean hemoglobin level and educational level and patients' age; children less than 12 years old who are still in early and late elementary school level have lower hemoglobin level than adolescents more than 13 years old and above who are in secondary school level. Theories of human growth and development are support this result like Erikson (1969), and Piaget (1970) and NKF-KDOQI, (2012) support this result related to children less need for physical development rather than adolescents' need during their growth spare. Low hemoglobin level has burden on many aspect of quality of life as psychosocial, cognitive as educational achievement, especially related to frequent school absenteeism and less follow up of its requirements. Also, this finding is congruent with (Kring, \& Crane, 2009; Jalambo, Hamed, \& Abed, 2012). Jalambo, et al. (2012) they mentioned that female adolescent have low hemoglobin level were complaining of decline their educational achievement.

The finding of this study revealed that there is a significant difference in mean hemoglobin level and central line access as a vascular access through hemodialysis procedure lower than arteriovenous fistula and/or shunt this related to large amount of blood loss during connection the tubes for hemodialysis machine during each session of dialysis . Hemorrhage is one of acute complications may be happen at time of insertion of central lines lead to low hemoglobin level (Bessereau et al., 2010). Long-term complications such as clot formation caused blood loss (Vats, 2012). Treatment and preventing clot formation also lead to blood loss (Vats, 2012). So based in the current finding, if there are most difficult cases, an arteriovenous fistula should be best choice rather than central catheter, even if there are most tricky cases.

\section{Conclusion}

The value system in relation to the expectations, standards, goals and concerns of daily life within the context of the culture is defined as persons' awareness of quality of life (Finkelstein, Wuerth, \& Finkelstein, 2009).Children and adolescent are needed to maintain hemoglobin within certain level for growth and development in definite time of their life. While present disease such as ESRD might be affect their growth and their quality of life. This study is recommend as Unger and his colleagues suggested in their study that using the drug erythropoiesis-stimulating agent for anemia in ESRD patient has benefit effect for improving patients' quality of life (Unger et al., 2010).

Nurses who working at hemodialysis units are able to play in initiating dialogue with children and adolescents patients to examine and assess their health care needs especially related to nutritional and exercises program for ESRD. They could be organize especial daily activity programs for them based on hemoglobin level which will reflecting on quality of life for those children and adolescents. The findings of current study will enhance patients' self-esteem empowerment between other people and health care providers of improving health care outcomes for children and adolescents through their lived experiences and quality of life (Kinchen \& Powe, 2001; Kring \& Crane, 2009; Morsch et al., 2006).

\section{Limitation and Strengths of the Study}

The small convenience sample and cross-sectional design were the limitations of this study. There are many factors can affect quality of life; but Fatigue was the only sub score from that correlated with hemoglobin level and its 
effects on ESRD children and adolescents' quality of life was measured. Collecting more sequential hemoglobin levels throughout the course of dialysis may have shown a better correlation. Children and adolescents with ESRD often have several other co-morbidities which were not evaluated by this study which may have a correlation with QoL. As questionnaires were completed at the beginning of dialysis treatment, scoring of quality of life may have been affected by the side effects of the treatment than particular day.

\section{Acknowledgements}

The author is grateful thank children/parents for their cooperative, participation and their time to be part in this study, also thankful for directors and nurses at all hospital for their permission to publish this study .The author is appreciative to the Applied Science Private University, Amman, Jordan, for the financial support granted to cover the publication fee of this research article.

\section{Competing Interests Statement}

The author(s) declare that there is no competing or potential conflict of interest.

\section{References}

Abdelkader, R., Khalil, A., Masada R., Al-Klube, M., \& Alrimawi, I. (2016). Exploring the Quality of Life of Jordanian Children and Adolescents with End Stage Renal Disease Receiving Hemodialysis. European Scientific Journal, 12(35), 169- 187. https://doi.org/10.19044/esj

Al-Uzri, A., Matheson, M., Gipson, D. S., Mendley, S. R., Hooper, S. R., Yadin, O., \& Gerson, A. C. (2013). The Impact of Short Stature on HRQoL in Children with Chronic Kidney Disease. The Journal of Pediatrics, 163(3), 736-741. https://doi.org/10.1016/j.jpeds.2013.03.016

Ameringer, S., Elswick, R. K., \& Smith, W. (2013). Fatigue in Adolescents and Young Adults With ickle Cell Disease. Biological and Behavioral Correlates and Health-Related Quality of Life. Journal of Pediatric Oncology Nursing, 31(1), 6-17. https://doi.org/10.1177/1043454213514632

Benoist, B., McLean, E., Egli, I., \& Cogswell, M. (WHO). (2008). Worldwide prevalence of anemia 1993-2005: WHO global database on anemia.

Bessereau, J., Genotelle, N., Chabbaut, C., Huon, A., Tabah, A., Aboab, J., Chevret, S., et al. (2010). Long-term outcome of iatrogenic gas embolism. Intensive Care Medical, 36(7), 1180-1187. https://doi.org/10.1007/s00134-010-1821-9

Bossola, M., Vulpio, C., \& Tazza, L. (2001). Fatigue in Chronic Dialysis Patients. Seminars in Dialysis, 24(5), 550-555.

Bunn, H. (2011). Approach to the Anemias In: Goldman, L., Schafer, Al. (Eds.), Cecil Medicne (24th ed., Chapter 161). Philadelphia, Pa: Saunders Elserniers.

Clarkson, K., \& Robinson, K. (2010). Life on dialysis: A lived experience. Nephrology nursing journal 37(1), 29-35. PMID: 20333901

Chao, C, Huang J, Chiang C, \& COGENT (Cohort of Geriatric Nephrology in NTUH) study group. (2016). Functional assessment of chronic illness therapy - the fatigue scale exhibits stronger associations with clinical parameters in chronic dialysis patients compared to other fatigue-assessing instruments. Peer Journal, 4, 1-16. https://doi.org/10.7717/peerj.1818

Finkelstein, F., Wuerth, D., \& Finkelstein, S. (2009). Health-related quality of life and the CKD patient: Challenges for the nephrology community. Kidney International, 76(9), 946-952. https://doi.org/10.1038/ki.2009.307

Gat-Yablonski, G., \& Phillip, M. (2015). Nutritionally-induced catch-up growth. Nutrients, 7(1), 517-551 https://doi.org/10.3390/nu7010517

Geer, J., Lee, J., Morris, J., Srivaths, P., Eileen Brewer, E., \& Swartz, S. (2017). Standardized IV iron dos improved anemia management without adverse events in pediatric (ped) patients (pts) maintained on chronic hemodialysis (HD). Journal of Hemodialysis International, 21(1), 1-54.

Gerson. A., Hwang, .W., Fiorenza, J., Barth, K., Kaskel, F., et al. (2004). Anemia and health-related quality of life in adolescents with chronic kidney disease. American Journal of kidney Disease, 44(6), 1017-1023. https://doi.org/10.1053/j.ajkd.2004.08.024

Glader, B. (2007). The Anemias. In Kliegman, R. M., Behrman, R. E., Stanton, B. F. (Eds.), Nelson Textbook of Pediatrics (18th ed., Saunders pp. 2003-2006). Philadelphia. 
Goldstein, S., Rosburg, N., Warady, B., Seikaly, M., McDonald, R., Limbers, C., \& Varni, J. (2009). Pediatric end stage renal disease health-related quality of life differs by modality: A PedsQL ESRD analysis. Pediatric Nephrology, 24(8), 1553-1560. https://doi.org/10.1007/s00467-009-1174-1

Hockenberry, M. J., Rodgers, C., \& Wilson, D. (2017). Wong's essentials of pediatric nursing (10th ed.). St Louis: Mosby.

Ingulli, E. G., \& Mak, R. H. (2014). Growth in children with chronic kidney disease: role of nutrition, growth hormone, dialysis, and steroids. Current Opinion in Pediatric, 26(2), 187-192. PMID: 24535500. https://doi.org/10.1097/MOP.0000000000000070

Jalambo, M., Hamed, A., \& Abed, Y. (2012). Anemia and risk factors among female secondary students in the Gaza Strip. Journal of Public Health, 21(3). https://doi.org/10.1007/s10389-012-0540-9

Janus, J., \& Moerschel S. K. (2010). Evaluation of anemia in children. American Family Physician, 81(12), 1462-1471.

Jhamb, M., Argyropoulos, C., Steel, J. L., Plantinga, L., Wu, A. W., Fink, N. E., .. \& Unruh, M. L. (2009). Choices for Healthy Outcomes in Caring for End-Stage Renal Disease (CHOICE) Study.(2009). Correlates and outcomes of fatigue among incident dialysis patients. Clinical Journal of the American Society of Nephrology, 4(11), 1779-1786. https://doi.org/10.2215/CJN.00190109

KDOQI, Kidney Disease: Improving Global Outcomes (KDIGO). (2012). Anemia Work Group KDIGO Clinical Practice Guideline for Anemia in Chronic Kidney Disease. Kidney International. Supp 2(4), 279-335.

Kępka, A., Szajda, S. D., Stypułkowska, A., Waszkiewicz, N., Jankowska, A., Chojnowska, S., \& Zwierz, K. (2008). Urinary fructose-1, 6-bisphosphatase activity as a marker of the damage to the renal proximal tubules in children with idiopathic nephrotic syndrome. Clinical chemistry and laboratory medicine, 46(6), 831-835. https://doi.org/10.1038/kisup.2012.37

Kinchen, K., \& Powe, N. (2001). Measuring and managing health outcomes and quality of care in end-stage renal disease. Disease Management \& Health Outcomes, 9(9), 483-493. https://doi.org/10.2165/00115677200109090-00003

Kliger, A. S., Foley, R. N., Goldfarb, D. S., Goldstein, S. L., Johansen, K., Singh, A., \& Szczech, L. (2013). KDOQI US commentary on the 2012 KDIGO Clinical Practice Guideline for Anemia in CKD. American Journal of Kidney Diseases,62(5), 849-859. https://doi.org/10.1053/j.ajkd.2013.06.008

Kogon, A. J., Matheson, M. B., Flynn, J. T., Gerson, A. C., Warady, B. A., Furth, S. L., ... \& Goebel, J. (2016). Depressive symptoms in children with chronic kidney disease.The Journal of pediatrics, 168, 164-170. https://doi.org/10.1016/j.jpeds. 2015.09 .040

Koshy, S. M., \& Geary, D. F. (2008). Anemia in children with chronic kidney disease. Pediatric Nephrology, 23(2), 209-219. https://doi.org/10.1007/s00467-006-0381-2

Kring, D., \& Crane, P. (2009). Factors affecting quality of life in persons on hemodialysis. Nephrology Nursing Journal, 36(1), 15-25. PMID:19271620.

Locatelli, F., Bárány, P., Covic, A., De Francisco, A., Del Vecchio, L., Goldsmith, D., ... \& Van Biesen, W. (2013). Kidney Disease: Improving Global Outcomes guidelines on anaemia management in chronic kidney disease: A European Renal Best Practice position statement. Nephrology Dialysis Transplantation, 28(6). https://doi.org/10.1093/ndt/gft033

Massengill, S. F., \& Ferris, M. (2014). Chronic kidney disease in children and adolescents. Pediatrics in review, 35(1), 16-29. https://doi.org/10.1542/pir.35-1-16

National Clinical Guideline Centre.(2015). Anemia management in chronic kidney disease: NICE guideline 8. National Institute for Health and Care Excellence (NICE). https://doi.org/10.1503/cmaj.130363

National Kidney Foundation. (2006). KDOQI clinical practice guidelines and clinical practice recommendations for anemia in chronic kidney disease. American Journal Kidney of Diseas, 47(3), S11-S145.

Nelson R. G., \& Tuttle, K. R. (2007) The New KDOQI SUPPL Clinical Practice Guidelines and Clinical Practice recommendation for diabetes and CKD. Blood Purification, 25(1), 112-114. https://doi.org/10.1159/000096407

Nesrallah, G. E., Mustafa, R. A., Clark, W. F., Bass, A., Barnieh, L., Hemmelgarn, B. R., ... \& Sood, M. M. (2014). Canadian Society of Nephrology 2014 clinical practice guideline for timing the initiation of chronic dialysis. 
Canadian Medical Association Journal, 186(2), 112-117. https://doi.org/10.1503/cmaj.130363

Padhi, S., Glen, J., Pordes, B. A., \& Thomas, M. E. (2015). Management of anaemia in chronic kidney disease: summary of updated NICE guidance. BMJ: British Medical Journal (Online), 350. https://doi.org/10.1136/bmj.h2258

Park, K. S., Hwang, Y. J., Cho, M. H., Ko, C. W., Ha, I. S., Kang, H. G., ... \& Cho, H. Y. (2012). Quality of life in children with end-stage renal disease based on a PedsQL ESRD module. Pediatric Nephrology, 27(12), 2293-2300. https://doi.org/10.1007/s00467-012-2262-1

Polit, D. F., \& Beck, C. T. (2008). Nursing research: Generating and assessing evidence for nursing practice. Lippincott Williams \& Wilkins.

Seliger, S. L., Davis, C., \& Stehman-Breen, C. (2001). Gender and the progression of renal disease. Current $\begin{array}{lllll}\text { opinion in nephrology and } & \text { 219-225. }\end{array}$ https://doi.org/10.1097/00041552-200103000-00010

Seppi, T., Prajczer, S., Dörler, M. M., Eiter, O., Hekl, D., Nevinny-Stickel, M., ... \& Lechner, J. (2016). Sex differences in renal proximal tubular cell homeostasis. Journal of the American Society of Nephrology, 27(10), 3051-3062. https://doi.org/10.1681/ASN.2016040454

Silbiger, S. R., \& Neugarten, J. (2003). The role of gender in the progression of renal disease. Advances in renal replacement therapy, 10(1), 3-14. https://doi.org/10.1053/jarr.2003.50001

Unger, E. F., Thompson, A. M., Blank, M. J., \& Temple, R. (2010). Erythropoiesis-stimulating agents - time for a reevaluation. New England Journal of Medicine, 362(3), 189-192. https://doi.org/10.1056/NEJMp0912328

Vats, H. S. (2012). Complications of catheters: tunneled and nontunneled. Advances in chronic kidney disease, 19(3), 188-194. https://doi.org/10.1053/j.ackd.2012.04.004

Warady, B. A., Neu, A. M., \& Schaefer, F. (2014). Optimal care of the infant, child, and adolescent on dialysis: 2014 update. American Journal of Kidney Diseases, 64(1), 128-142. https://doi.org/10.1053/j.ajkd.2014.01.430

Wang, M. (2016). Iron Deficiency and Other Types of Anemia in Infants and Children. American family physician, 93(4).

\section{Copyrights}

Copyright for this article is retained by the author(s), with first publication rights granted to the journal.

This is an open-access article distributed under the terms and conditions of the Creative Commons Attribution license (http://creativecommons.org/licenses/by/4.0/). 